\title{
CORRELATION BETWEEN MICROSTRUCTURE AND MECHANICAL PROPERTIES OF ESCALATOR STEPS MADE BY HIGH PRESSURE DIE CASTING
}

J. Asensio*, J. J. del Campo**, B. Suárez*

*The University of Oviedo, Department of Materials Science and Metallurgical Engineering, School of Mines, 13 Independence St., E-33004 Oviedo, Spain.

**Formerly at Thyssen-Krupp Guss, S.A. Polígono Industrial Vega de Baíña, E-33682 Mieres, Spain

Aluminium-Silicon eutectic and quasi-eutectic alloys exhibit an excellent fluidity and a low tendency to develop micro-shrinkage, resulting in sound components of high compactness. With regard to its mechanical behaviour the eutectic composition show relatively poor mechanical properties, which only suffice to certain static applications: $\sigma_{\mathrm{y}}(190-200 \mathrm{MPa}), \sigma_{\mathrm{TS}}(240-260 \mathrm{MPa})$ and low ductility $\left(\mathrm{A}_{\mathrm{T}}\left(\mathrm{l}_{0}=50\right.\right.$ $\mathrm{mm})<1 \%$ ) [1]. The addition of small quantities of microalloying elements such a Strontium has been extensively reported in the technical literature to improve the ductility [2]. The effect of this element is evident through the modification of the acicular shaped eutectic Silicon into rounded morphologies [3], the dispersion of the primary Silicon cuboids of smaller sizes, and the development of a fully dendritic Al- $\alpha$ structure with long primary dendrite arms and very small less developed secondary dendrite arms. Titanium and Boron are often added to Al-Si castable alloys to promote the refinement of the Al- $\alpha$ dendrites. The most common commercial alloy added to pure Al and many other Aluminium melts is the Al-5Ti-1B master alloy [4]. It provides the formation of solid precipitates of $\mathrm{TiB}_{2}$ and $/$ or $\mathrm{TiAl}_{2}$. in the liquid, serving for grain refinement by providing heterogeneous nucleation sites for Al- $\alpha$ during solidification. Yet variations of the former mother alloy such as Al-3Ti-3B and Al-3Ti-1B have proved more efficient for Al-Si alloys of more than 7\% Si [5].

In the present work two objectives were aimed at: firstly to show the effectiveness of the modification process with $\mathrm{Sr}$ added to the Al-12\% Si commercial alloy, and/or the addition of grain refiners containing $\mathrm{Ti}$ and $\mathrm{B}$. Followed by the characterization of the resulting microstructural parameters of pressure die cast components (Figure 1). The second one, targeted on the evaluation of the mechanical properties and its correlation to the microstructure parameters. The samples evaluated correspond to specimens cut from elevator steps produced in short runs of the industrial route followed at the Thyssen-Krupp Guss foundry facilities located in Mieres, Asturias (Spain). The commercial alloy used to obtain the escalator steps was Al-12\%Si (Table 1) to which after complete melting - prior to degassing- Al-3Ti-1B (TiBAl 3/1) was added as grain refiner and/or Al-10\% Sr as alloy modifier. They both come in the form of rods of small diameter and were simply thrown to the melt followed by mechanical stirring (Table 2). This table also shows the summary of results of the tensile tests of a sample cut from the central ledger of the step with and without the addition of microalloying elements (Ti, B, and $\mathrm{Sr}$ ).

[1] ASM International, Aluminium and Aluminium Alloys, $3^{\text {rd }}$ ed., Materials Park OH, 1994.

[2] L. Hengcheng and S. Guoxiong, Scripta Mater. 48 (2003) 1035.

[3] H. Liao, Y. Sun and G. Sun, J. Mater. Sci.37 (2002) 3489.

[4] J. E. Gruzleski, Microstructure Development during Metal Casting, American Foundrymen Society, U.S.A., 2000.

[5] T. Sritharan and H. Li, J Mater Process Tech. 63 (1997) 585. 
Table 1. Chemical composition of the Al-12\% Si commercial alloy used in the present work.

\begin{tabular}{|c|c|c|c|c|c|c|c|c|c|c|c|}
\hline Elements & $\mathrm{Si}$ & $\mathrm{Fe}$ & $\mathrm{Cu}$ & $\mathrm{Mn}$ & $\mathrm{Mg}$ & $\mathrm{Ni}$ & $\mathrm{Zn}$ & $\mathrm{Pb}$ & $\mathrm{Ti}$ & Other & $\mathrm{Al}$ \\
\hline$\%$-weight & 12.90 & 0.82 & 0.04 & 0.20 & 0.01 & 0.006 & 0.03 & 0.02 & 0.008 & 0,036 & 85,93 \\
\hline
\end{tabular}

Table 2. Microstructural feature results and Mechanical properties of the experimental materials.

\begin{tabular}{|c|c|c|c|c|c|}
\hline \multirow{2}{*}{$\begin{array}{l}\text { EXPERIMENTAL } \\
\text { MATERIAL }\end{array}$} & \multicolumn{2}{|c|}{$\begin{array}{l}\text { MICROSTRUCTURAL } \\
\text { FEATURES }\end{array}$} & \multicolumn{3}{|c|}{$\begin{array}{c}\text { TENSILE MECHANICAL } \\
\text { PROPERTIES }\end{array}$} \\
\hline & $\begin{array}{l}V_{V}(\alpha) \\
(\%)\end{array}$ & $\begin{array}{c}\bar{A}_{\alpha} \\
\left(\mu \mathrm{m}^{2}\right)\end{array}$ & $\begin{array}{c}\sigma_{\mathrm{y}} \\
(\mathrm{MPa})\end{array}$ & $\begin{array}{c}\sigma_{\mathrm{TS}} \\
(\mathrm{MPa})\end{array}$ & $\begin{array}{l}\mathrm{A}_{\mathrm{T}} \\
(\%)\end{array}$ \\
\hline AlSi 12 & 46.23 & 553 & 65.0 & 141.5 & 0.96 \\
\hline AlSi $12+0.024 \% \mathrm{Ti}$ & 43.59 & 364 & 77.1 & 145.7 & 1.40 \\
\hline AlSi $12+0.02 \% \mathrm{Sr}$ & 48.51 & 204 & 62.3 & 145.3 & 1.69 \\
\hline AlSi $12+0.03 \% \mathrm{Ti} / 0.04 \% \mathrm{Sr}$ & 48.20 & 314 & 65.5 & 148.8 & 1.41 \\
\hline AlSi $12+0.04 \% \mathrm{Ti} / 0.04 \% \mathrm{Sr}$ & 53.48 & 307 & 80.0 & 154.0 & 1.39 \\
\hline
\end{tabular}
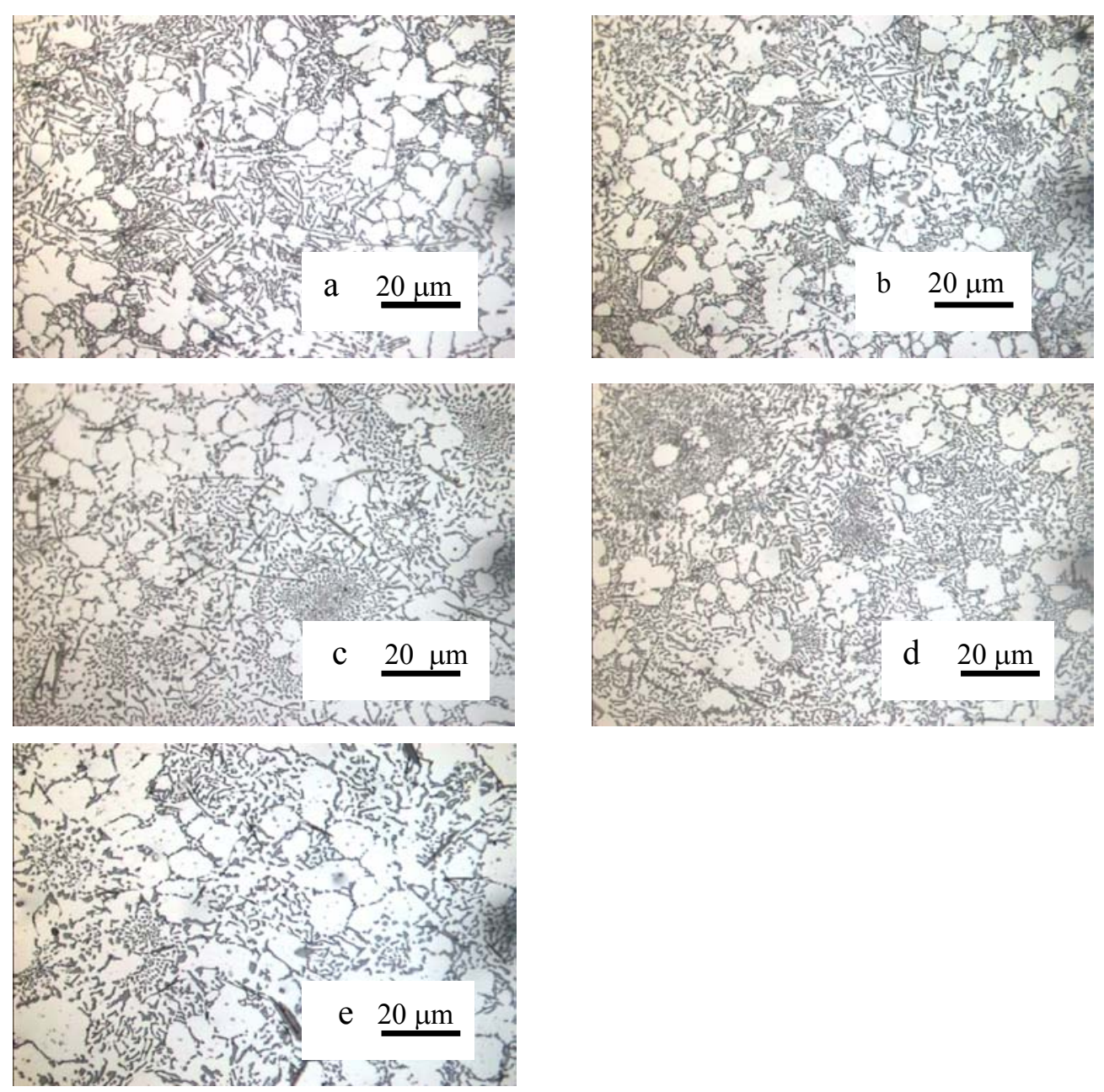

Fig.1. Corresponding optical microstructures to the experimental materials analysed: (a) AlSi 12; (b) AlSi $12+0.024 \% \mathrm{Ti}$; (c) AlSi $12+0.02 \%$ Sr; (d) AlSi $12+0.03 \% \mathrm{Ti} / 0.04 \% \mathrm{Sr}$; (e) AlSi $12+0.04 \%$ $\mathrm{Ti} / 0.04 \% \mathrm{Sr}$. 